\title{
REDUCING HEALTH INEQUALITIES AS A COMPONENT OF THE HEALTH TRAINING PROGRAMS
}

DOI: 10.36740/WLek202005118

\author{
Tetiana S. Gruzieva', Nataliia V. Hrechyshkina', Mykhailo D. Diachuk², Vasyl A. Dufynets ${ }^{3}$ \\ 'BOGOMOLETS NATIONAL MEDICAL UNIVERSITY, KYIV, UKRAINE \\ 2STATE INSTITUTION OF SCIENCE «RESEARCH AND PRACTICAL CENTER OF PREVENTIVE AND CLINICAL MEDICINE» STATE ADMINISTRATIVE DEPARTMENT, \\ KYIV, UKRAINE \\ ${ }^{3}$ OPHTHALMIC CENTER «VIZIS EXCLUSIVE», MUKACHEVO, UKRAINE
}

\begin{abstract}
The aim: identifying the characteristics and trends of inequalities in the health of the population to substantiate the educational content of the curriculum for the training of Master in Public Health.

Materials and methods: Bibliographic, sociological, medical-statistical and information-analytical methods were used in the study. Ukraine's healthcare institutions were the scientific base of the study. The data on the average life expectancy, morbidity, mortality, satisfaction of medical needs of different groups of the population for revealing the social gradient are analyzed. Documents on strategies to reduce health inequalities have been examined.

Results: Health inequalities between WHO countries have been identified, including a difference in the average life expectancy at birth of 17.1 years in premature mortality due to differences in the levels of economic development of countries. The inequality in the prevalence of diseases and the difference in the satisfaction of specific medical needs among the first and tenth decile population of Ukraine were determined. The prevalence of diseases of the genitourinary system in the population older than 60 years with low rates by $27.3 \%$ was higher than the figure among financially insured persons. The incidence of ocular pathology among adults with different income levels varied 1.8 times. The provisions of the WHO strategic documents on reducing health inequalities and its protection and on developing the public health system are analyzed. We justify the necessity of expanding the coverage of the problems of reducing disparities in health and health care in the course of training of the Master in Public Health. A modern curriculum "Social Medicine, Public Health" has been developed with the inclusion of inequalities in public health and appropriate educational and methodological support.

Conclusion: The strategic goal of reducing inequalities in public health and its care requires integrating these issues into a modern master's in public health program. The curriculum developed covers various aspects of health inequalities and health care, including the identification and assessment of disparities, the clarification of causes, the identification of counter-measures. Created educational and methodological support allows acquiring theoretical knowledge and practical skills that form the necessary competencies of professionals in the context of overcoming inequalities in health.
\end{abstract}

KEY WORDS: health inequality, morbidity, disease prevalence, mortality, average life expectancy, social determinants, poverty, inequality reduction strategies, curriculum

Wiad Lek. 2020;73(5):937-942

\section{INTRODUCTION}

In the current conditions of development of science and society, significant changes have been made in improving the health indicators of the population, as evidenced by the increase in life expectancy, reduction of infant mortality, premature mortality, mortality from infectious diseases, etc. Positive changes in population health indicators are observed at global, regional, national and local levels [1-3].

An analysis of the current situation in the countries of the WHO European Region in achieving the Health 2020 target points to a $9 \%$ reduction in the population mortality rate between 30-69 years of age in 2010-2015, a premature death rate from four leading non-communicable diseases - to $10 \%$, deaths from external causes - by $12.3 \%$. Infant mortality decreased by $6.8 \%$ over the specified period in the Region; life expectancy increased from 76.7 to 77.9 years [4].

However, such progress has not been made universally. There are significant differences in the countries and the individual population groups within a country in the health of the population and its protection. It is known that not all differences in health indicators are manifestations of inequality. Variations due to unhealthy living and working conditions, harmful behavior, when the degree of lifestyle choice is limited, lack of access to medical and social care, are unfair and are considered manifestations of inequality [5-8].

A significant role in the formation of health inequality and its protection is played by social and economic determinants, including the level of education, official position, income level, etc. Scientific literature indicates a significant effect of these determinants on the formation of the scale of inequality. Thus, women and men from the poorest $20 \%$ of the population are almost twice as likely to report diseases that limit their freedom in daily activities, compared with those belonging to the poorest $20 \%$ of the population. In most European countries, women 
with low levels of education have poorer health outcomes than women with higher levels of education. In the most disadvantaged areas, $4 \%$ more children do not live by the first anniversary, compared with the prosperous areas. In the poorest households, $22 \%$ more women 65 years of age and older and $21 \%$ more men complain of poor health compared to the richest households [9-11].

Confirmation of the relevance of this problem for Ukraine is the study of differences in the health of different groups of the population depending on socio-economic status. Based on data from a large-scale study of population health in different regions of the country, differences in the incidence rates of populations with different levels of material wealth were established. In low-income strata of the population compared with the wealthy, levels of the prevalence of chronic pathology were $55.6 \%$ higher according to medical examinations, lower indicators of self-esteem of health and quality of life, a greater need for health services [12-13].

Given the prevailing trends, the priority task of all countries is to reduce social inequality and its negative impact on public health. Commission on the Social Determinants of Health calls on the world community to close the health gap over the course of a generation [14].

Realizing this important task requires expanding the evidence base to establish the extent of inequalities in the health of the population and its protection, trends and choose optimal strategies to reduce manifestations of health inequities.

To reduce manifestations and eliminate inequalities in health, joint actions of numerous stakeholders, strategies and programs that can influence various complex decision-making processes within these structures are necessary. In modern conditions, before the systems of health care, education and science, social security, etc. important challenges arise to improve the determinants of health. The three main lines of action recommended by WHO include improving daily living conditions; overcoming the unfair distribution of power, money, resources; measuring and understanding the extent of the problem and assessing the consequences of actions [15-18].

In the context of these areas, the problem of forming the personnel potential of healthcare is considered. The need to solve the problem is due to the fact that health care professionals must understand what differences in health are manifestations of inequality, be able to identify the causes and determinants of the formation of inequality in health, know the methodology for measuring inequality in health and modern strategies for reducing it.

Given the above, studies of modern features of manifestations of inequalities in health and its protection for the formation of modern educational programs for training personnel are relevant.

\section{THE AIM}

Aim is establishing the characteristics and trends of inequality in the health of the population to justify the educational content of the curriculum for the training of Masters of Health.

\section{MATERIALS AND METHODS}

When performing the study, bibliographic, sociological, medical-statistical and information-analytical methods were used. The scientific basis of the study was the healthcare institutions of Ukraine. The data on the average life expectancy, morbidity, prevalence of diseases, mortality of various segments of the population, satisfaction of their medical needs to identify the social gradient are analyzed. The indicators of accessibility of medical care for various population groups are estimated. The WHO strategic documents on reducing and overcoming inequalities in public health are analyzed. The priority problems of the educational support for the training of health professionals on these issues and the reasonably relevant content of the curriculum for the training of Masters of Health are identified.

\section{RESULTS}

An analysis of the European database "Health for All" revealed differences in life expectancy at birth and in mortality rates among countries in the WHO European Region.

So, the highest average life expectancy in 2015 was observed in Switzerland (83.4 years), Spain (82.8 years), Italy (82.7 years), Israel ( 82.5 years), France ( 82.4 years), Norway (81.5 years). At the same time, the lowest rates were found in Turkmenistan (66.3 years), Uzbekistan (69.4 years), Tajikistan (69.7 years). The difference in life expectancy at birth was 17.1 years.

These demographic data are correlated with economic indicators. There is a clear correlation of the average life expectancy on the level of economic development of countries. Gross domestic product (GDP) per person per year in 2015 amounted to 82.0 thousand dollars in Switzerland, in Norway - 74.5 thousand dollars, Israel -35.7 thousand dollars, France -36.6 thousand US dollars, Italy - 30.2 thousand US dollars. Spain - 25.8 thousand US dollars, respectively. And in countries with low average life expectancy, the GDP per person per year was equal in Tajikistan - 0.9 thousand US dollars, in Kyrgyzstan - 1.1 thousand US dollars, in Uzbekistan - 2.1 thousand US dollars, in Turkmenistan -6.4 thousand US dollars.

The dependence of the average life expectancy on the level of economic development of the countries of WHO / Europe by country groups is quite clearly traced. So, in 2015 , countries included in the information network of the Central Asian countries (CAR) had the lowest GDP per person per year (4.4 thousand US dollars), the lowest average life expectancy (69.6 years) and high mortality rate of the population aged $0-64$ years (395 cases per 100 thousand). In the new independent countries (NIS), the higher GDP per person per year (6.6 thousand US dollars) correlated with longer life expectancy (70.6 years). The same pattern was observed in the countries of the network of Southeast Europe (SEE): the growth of GDP per person per year up to $\$ 10.9$ thousand coincided with an increase in average life expectancy of up to 76.3 years compared to NIS countries. At the same time, in the countries of the 

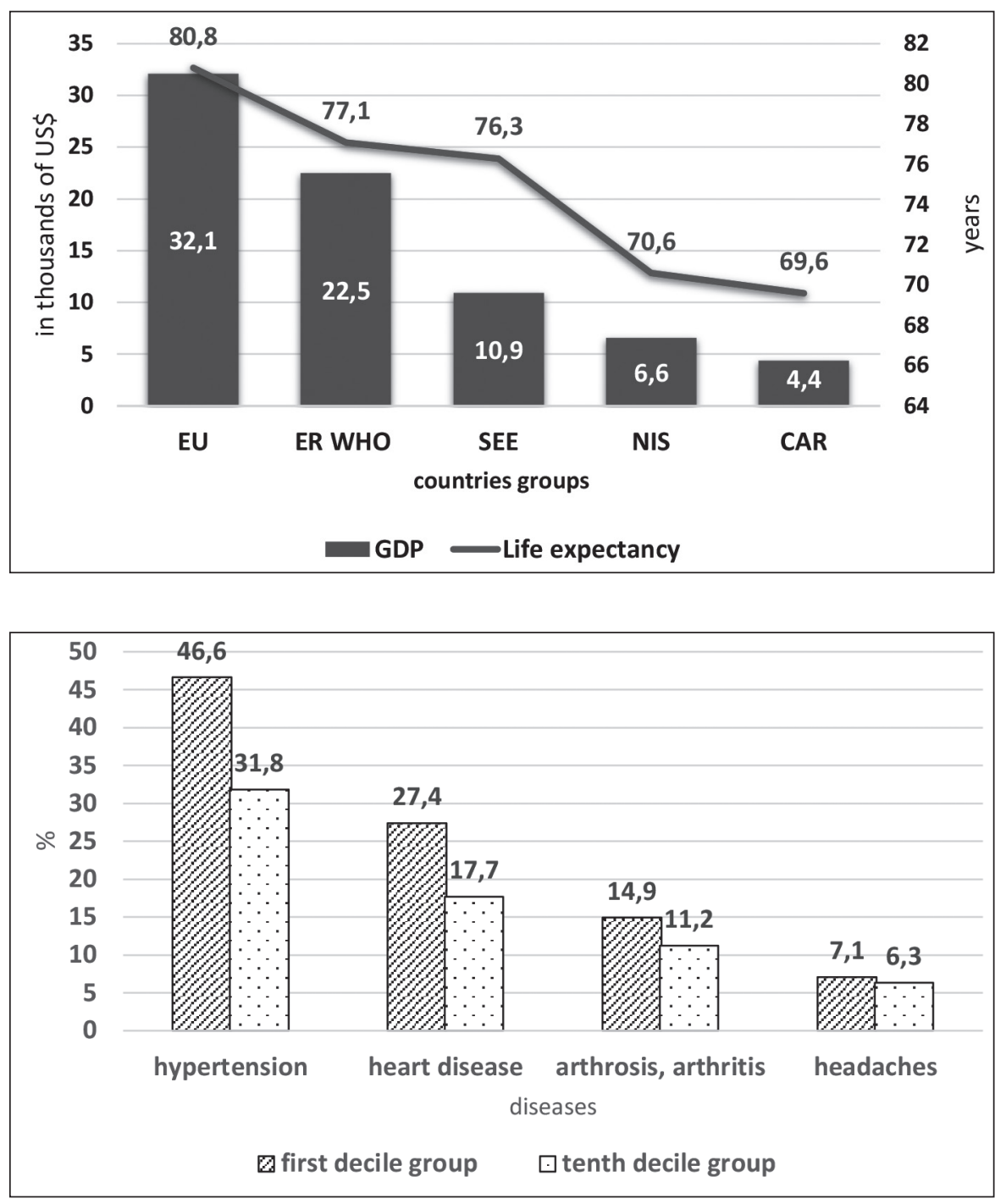

Fig.1. Differences in the groups of countries in WHO / Europe in terms of GDP per person per year (thousand US dollars) and average life expectancy (years) in 2015.
Fig.2. The proportion of people with health problems in various decile groups of the population, depending on the size of per capita total income in 2017 (\%).

Table I. The proportion of people who did not receive the necessary medical care in households in Ukraine with different levels of average per capita total income, in 2010 and 2017 years (according to the State Statistics Service of Ukraine)

\begin{tabular}{|c|c|c|c|c|}
\hline \multirow{2}{*}{ Indicator } & \multicolumn{2}{|c|}{ I decile group (\%) } & \multicolumn{2}{|c|}{ X decile group (\%) } \\
\hline & 2010 & 2017 & 2010 & 2017 \\
\hline $\begin{array}{l}\text { The number of households in which one of the } \\
\text { members for } 12 \text { months, if necessary, could not receive } \\
\text { medical care, medicines, supplies }\end{array}$ & 16,5 & 35,1 & 8,3 & 16,6 \\
\hline
\end{tabular}

European Union (EU), the GDP per person per year was the largest among other groups of WHO ER countries (32.1 thousand US dollars), the average life expectancy was 80.8 years, and premature mortality was minimal (182 per 100 thousand) (Fig. 1).

Analysis of data from the State Statistics Service of Ukraine for 2010-2017 revealed the presence of a social gradient in the health of the population and its protection, depending on the income levels of citizens.

Thus, in the first decile group of the population, $46.6 \%$ of the respondents indicated the presence of hypertension, $31.8 \%$ in the tenth decile group; $27.4 \%$ and $17.7 \%$ for the presence of heart disease, $14.9 \%$ and $11.2 \%$ for arthrosis, arthritis, headaches $-7.1 \%$ and $6.3 \%$, respectively (Fig.
2.). In the first decile group, the proportion of patients with cataracts, stroke, osteoporosis, depression and the like was greater.

It was revealed that the proportion of people who did not receive medical care or did not purchase medicines or medical equipment, although they had a need for it, among households of the I decile group is much higher than among the $\mathrm{X}$ decile group (35.1\% and 16.6\%) (table I.). An analysis of the data also indicates a greater share of unmet medical needs in 2017 compared to 2010 in both the first and tenth decile populations.

The difference was also found in the dissatisfaction of specific medical goals, including in visiting a doctor, in medical examinations, prosthetics, medical procedures, 
in-patient treatment in various decile groups of the population by income level. Moreover, the overwhelming reason for the unmet needs was their high cost.

A comparison of statistics revealed an increase in the ratio of the minimum level of total income among the tenth decile group of the population to the maximum level of income among the first decile group of the population from 2.6 in 2017 to 2.9 times - in 2018. Among urban residents, stratification increased from 2, 6 to 3 times, among rural - from 2.7 to 2.8 times. At the same time, the total income of the poorest 10\% of the population in 2018 was 4.7 times higher than the income of $10 \%$ of the poorest citizens. In urban areas, this excess was 4.8 times, in rural areas -4.2 times.

An analysis of the questionnaire results of patients from a multidisciplinary healthcare institution showed differences in the prevalence of the urogenital system in patients older than 60 years, depending on the level of material wealth. So, who rated the level of material support as insufficient, the prevalence of diseases of the genitourinary system was $105.5 \pm 11.0$ per 1000 , among those who rated it as sufficient $-82.9 \pm 11.2$ per 1000 people of the corresponding age.

A sociological study conducted among patients of an ophthalmological healthcare institution revealed a high incidence of ophthalmic pathology $(76.9 \pm 8.6$ per 1000$)$ among the low-income population by self-assessment of their financial condition, compared with the financially secure group ( $43.5 \pm 8,2$ per 1000$)$.

\section{DISCUSSION}

Despite the existing manifestations of inequality in the health of the population and health protection in countries of different economic development levels and in different socio-economic groups of the population within the country, it is understandable that measures should be taken to reduce it.

The analysis of the strategic documents of the UN, WHO, WHO / Europe allows us to identify priority strategies for overcoming inequalities in health and its protection. The Sustainable Development Goals, endorsed by the UN General Assembly in 2015, are directly related to overcoming health inequalities. After all, they provide for the universal elimination of poverty in all forms, ensuring a healthy lifestyle and promoting well-being for all at any age, providing a quality education, and the like. The adopted document obliges member countries to develop their own strategies, plans and programs for sustainable development with specification of national targets. In Ukraine, the Sustainable Development Goals for the period until 2030 are approved by the Decree of the President of Ukraine.

The Health 2020: a European policy framework sets strategic goals for countries, one of which is to improve health and overcome health inequalities. The mechanism for the successful reduction of many health problems is the effect on the social and environmental determinants of health. The document notes that for effective interventions it is necessary to actively develop intersectoral cooperation and introduce integrated programs. At the same time, along with the national approach, it is necessary to implement the principle of participation of the whole society, with the involvement of all interested parties. The document identifies three main principles, which are improving daily living conditions, overcoming injustice at the global, national and local levels in the distribution of power, money and resources, as well as measuring the scale of problems, evaluating actions, expanding the knowledge base, and training people with skills in social determinants of health, raising public awareness of their importance. These lines of action are highlighted in several other WHO documents, in particular in the final report of the WHO Commission on the Social Determinants of Health, "Bridging the gap in a generation. adhering to the principle of equity in health by influencing the social determinants of health", resolutions of the World Health Assembly WHA 62.12 and WHA66.15, the Rio Declaration on the Social Determinants of Health, Evidence and resources to act on health inequities, social determinants and meet the SDGs like that.

Given the European and national context regarding inequities in the health of the population, the strategies to overcome it, as outlined in the UN, WHO, WHO / Europe documents, the issue of training health personnel with competencies to improve the social determinants of health and reduce inequalities in health is of particular relevance.

Given the current characteristics of public health and strategies for improving it at the Bogomolets National Medical University developed a sample curriculum for the discipline "Social Medicine, Public Health" with the inclusion of issues of health inequality and its protection.

In accordance with the theme of the new curriculum for training Masters of Health on inequality in health, its educational and methodological support was created, including theoretical material, methodological recommendations for teachers and students, practical tasks in the form of situational tasks, questions for test control and the like.

The educational content of this topic included issues of differences in health, inequalities in health, inequities in health and its protection, analysis of social determinants, determination of social gradient, justification of strategies to overcome inequalities in health.

Upon completion of the study of this topic, students will need to know the definition of the concepts of "inequality in health" "inequity in health", "social determinants", "social gradient"; causes and determinants of inequality in health; methodology for measuring health inequality; modern strategies to reduce inequalities in health. In a practical lesson, skills will be developed that will provide the ability to identify the extent of inequality in health; establish the causes of inequalities in health; identify priority measures to reduce inequalities in health and well-being.

The theoretical part of the material deals with the distinction between the concepts of differences in health and inequalities in health with a focus on injustice, illegality, which leads to inequality. Examples of differences and inequalities that characterize the extent of the inequitable 
distribution of health and the opportunities to protect it at the global, regional and national levels contribute to a better perception of the material. Such examples are the average life expectancy in countries of the world with different levels of economic development, morbidity, mortality in population groups with radically different levels of material income, education, social status and the like.

An essential aspect of the educational subject is understanding and the ability to determine the social gradient. A striking illustration of inequality in society is the traditional indicators of social inequality and differentiation, namely, decile and quintile coefficients, Lorentz distribution, Gini coefficient, and the like.

A separate block of questions concerns the driving forces of health inequity. In this context, the issues of shifts in social determinants in the process of social development, the problems of absolute and relative poverty, the verge of poverty, and the like are considered.

Mastering these aspects allows future masters to form a vision for equality in health matters. It is essential to understand the purpose of such activities, lines of action and specific measures to eliminate the differences in the health of different groups of the population, due to factors that are considered unlawful, unfair and which can be avoided.

The next stage of the thematic work is to consider the solution of a typical example to determine the extent of differences in health indicators, explain whether they are a manifestation of inequality in health, and develop measures to reduce disparities in health.

Practical work on the methodology for analyzing the causes of social inequality concerning health and its protection consists in determining by each student, according to the situational task, the extent of differences in the health of specific groups of the population, assessing them from inequality, justifying and developing measures to overcome disparities in health in the given situation tasks.

Evaluation of theoretical training on the topic "Methodology for the analysis of the causes of social inequality concerning health and its protection" provides for test control and an oral survey of students on the list of proposed questions, practical skills - based on the results of solving a situational problem.

The inclusion of new topics on inequality in health in the training of Masters of Public Health will help them master an essential component in ensuring the appropriate level of public health and use in future professional activities to provide interdisciplinary interaction and intersectoral cooperation.

\section{CONCLUSIONS}

So, the analysis of statistical data and data of our research indicates the existence of significant manifestations of inequality in the health of the population and its protection at different levels of health care. Overcoming disparities in health, which is a manifestation of injustice, is defined as one of the strategic objectives of health care and social development in general.
The solution to this strategic task requires the inclusion of issues of reducing inequality in the health of the population and its protection in the current training program for Masters in Public Health. The content of the curriculum should cover various aspects of the problem, including identifying and assessing the extent of health inequality, identifying the causes, identifying countermeasures.

Given the above, at the Bogomolets National Medical University developed a sample curriculum for the discipline "Social Medicine, Public Health" with the inclusion of issues of health inequality and its protection. Educational and methodological support was formed, including theoretical material, methodological recommendations for teachers and students, practical tasks in the form of situational tasks, questions for test control, and the like.

The inclusion of issues of inequality in the health of the population in the course of training for Masters of Health will increase the level of their theoretical and practical training and will form the necessary competencies for solving the strategic tasks of healthcare in the context of interdisciplinary interaction and intersectoral cooperation.

\section{REFERENCES}

1. World Health Statistics 2017: Monitoring health for the SDGs. Geneva: World Health Organization. 2017; 116.

2. Tracking universal health coverage: First global monitoring report. Geneva: World Health Organization. 2015; 98.

3. Health in 2015: from MDGs, Millennium Development Goals to SDGs, Sustainable Development Goals. Geneva: World Health Organization. 2015; 216.

4. European health report 2018. More than numbers - evidence for all. Copenhagen: WHO Regional Office for Europe. 2018; 164.

5. Marmot M. Review of social determinants and the health divide in the WHO European Region: final report. Copenhagen:WHO Regional Office for Europe. 2014; 234.

6. Report on health inequalities in the European Union. 2013; 45.

7. Better Health for Europe: more equitable and sustainable. Copenhagen: WHO Regional Office for Europe. 2019; 380.

8. Review of social determinants and the health divide in the WHO European Region, Updated reprint 2014. Copenhagen: WHO Regional Office for Europe. 2014.

9. Social determinants of health and well-being among young people : Health Behaviour in School-Aged Children (HBSC) study : international report from the 2009/2010 survey. Copenhagen: WHO Regional Office for Europe. 2012; 274.

10. Whitehead M., Povall S., Loring B. The equity action spectrum: taking a comprehensive approach. Guidance for addressing inequities in health. Copenhagen: WHO Regional Office for Europe. 2014.

11. Hosseinpoor A.R. et al. Socioeconomic inequality in the prevalence of noncommunicable diseases in lowand middle-income countries: results from the World Health Survey. BMC Public Health. 2012; 12:474.

12. Gruzieva T.S. Health inequality: methodology of definition, manifestations, strategies of struggle. Scientific Bulletin of the Bogomolets National Medical University. 2005; 1-2:33-42.

13. Gruzieva T.S. Reducing health inequalities and protecting them as a priority for health policy. Eastern European Journal of Public Health. 2012;1 (17):132-133. 
14. Closing the gap in a generation Health equity through action on the social determinants of health. Geneva: World Health Organization. 2008; 256.

15. Mackenbach J.P. The persistence of health inequalities in modern welfare states. The explanation of a paradox. Social Science and Medicine. 2012; 77:561-769.

16. Engagement and participation for health equity. Copenhagen: WHO Regional Office for Europe. 2017; 20.

17. Paula Franklin, Scott L. Greer, Michelle Falkenbach. Policy coherence as a driver of health equity. Copenhagen:WHO Regional Office for Europe. 2019; 34.

18. Evidence and resources to act on health inequities, social determinants and meet the SDGs / Copenhagen:WHO Regional Office for Europe. 2019; 72 .

The article was performed in frameworkof research "Public Health Service Personnel Scientific Rationale”, (2017-2019, №. of state registration 0117U002681), applied, initiative, financing of the Bogomolets National Medical University; and «Substantiation of the modern system of prevention of chronic noncommunicable diseases and formation of a healthy way of life», (2014-2016, № of state registration 0114U000508), financing of the Ministry of Health.

\section{ORCID and contributioship:}

Tetiana S. Gruzieva - 0000-0001-9254-7561 A,B,C,D,F

Nataliia V. Hrechyshkina - 0000-0002-9499-4362 ${ }^{\text {B,C,E,F }}$

Mykhailo D. Diachuk - 0000-0003-0390-4489 C,E

Vasyl A. Dufynets - ${ }^{D, E, F}$

\section{Conflict of interest:}

The Authors declare no conflict of interest

\section{CORRESPONDING AUTHOR}

Tetiana S. Gruzieva

National Bogomolets Medical University

Saksaganskogo St. 42/43, 01033 Kyiv, Ukraine

e-mail: gruzieva@ukr.net

Received: 31.01 .2020

Accepted: 02.04 .2020

A - Work concept and design, B - Data collection and analysis, C - Responsibility for statistical analysis,

$\mathbf{D}$-Writing the article, $\mathbf{E}$ - Critical review, $\mathbf{F}$ - Final approval of the article 